\title{
Understanding a Co-Evolution Model of Business and IT for Dynamic Business Process Requirements
}

\author{
Muhammad Asif Khan \\ Department of Information Systems \\ College of Computer Science and Engineering, Taibah University \\ Madinah al Munawwara, Saudi Arabia
}

\begin{abstract}
Organizations adapt existing business processes in order to become competitive but a change in a process affects other processes as well. In order to support the required change suitable technologies must be provided so that business could run smoothly and efficiently. Since in a dynamic business environment requirements are changed frequently it is difficult to update underlying technologies to support changes in business processes. This creates a gap between business and information technology (IT) that directly affects whole business. In this study requirements for a dynamic business and a co-evolution model are presented that may bring both the entities closer to bridging the gap in a dynamic business organization. The co-evolution model has been used in a financial institution and feasibility and viability of the model has been observed.
\end{abstract}

Keywords-alignment; business-IT gap; business process; coevolution

\section{INTRODUCTION}

Today a large number of companies are increasingly automating business processes with latest information technology (IT) in order to meet customers' requirements. Most of the organizations invest hefty budget for acquiring IT but fail to achieve the desired results in terms of return on investment. Researchers and practitioners found that absence of alignment between business and IT causes the failure to meet the desired goals of organizations. Earlier researchers focused on aligning business strategies and IT strategies [1]. Now alignment is studied at strategic, operational and IT project levels [2][3][4]. The main reason of the failure is that business requirements and IT evolve separately consequently the rate of evolution is different in both the entities. If the business requirements and underlying technologies co-evolve then they will have a significant impact on business. Technologies are continuously emerging that help to develop and improve business processes whereas the requirements coerce IT to be evolved in order to meet the business needs. An analysis of co-evolution requirements has been discussed in a study conducted by Khan \& Zedan [5] in which dependency, independency and interdependency between both the entities is discussed. In a dynamic business environment it is necessary that underlying technologies are evolved to support the business but due to continuous changes adaptability in technology is difficult and that affects the efficiency of the business. Therefore, an efficient dynamic business requires supporting IT to be evolved so when business requirements are changed the supporting software has to be evolved i.e. a coevolution should occur. Contrary to this if changing business requirements are not supported by the IT a gap is created due to absence of co-evolution in turn decrease in efficiency of the business happens. Morrison et al. [6] used the co-evolution term for describing evolution in both business and IT at different rate. Business requirements or supporting technologies are evolved due to internal or external changes. If the business processes are independent of each other the evolution is easy and each process can adjust it, but for coevolution business processes are interconnected and therefore, a change in a process affects other processes as well. To carry out business activities smoothly and effectively all the processes need to be co-evolved. Researchers and practitioners have demonstrated various models to bring both business and IT into alignment and the most well-known model is Strategic Alignment Model (SAM) in which alignment is observed at three levels within organizations [7]. In another study [8] presented three-layers model in a firm and discussed the business-IT alignment as a co-evolutionary process and asserted co-evolution occurs due to external changes and within organizational components. Earlier researchers and practitioners focused on aligning business strategies and IT strategies with the understanding that one could align the other [1]. In a study Chebrolu [9] assessed the relationship between strategic alignment and IT effectiveness in order to ascertain the dominance between the two constructs. Recently Suwatana, Winai, \& Do [10] presented both strategic and operational levels within organizations in order to align both business and IT. In a study Richard \& Lucy [11] described the importance of alignment between business strategy and IT strategy and stressed the need of technological readiness in terms of human resource before financial investment. Many studies have shown that IT investment has been effective in organizations' performance in different business areas [12]. A four-layer framework aimed at reducing gap between business and IT by considering requirements of business and information management rather information systems [13]. For business-IT alignment a conceptual model-driven approach has been presented by [25] that aim at restriction of freedom in process modeling. A model based on social, cultural and structure aspects was presented in order to achieve alignment between business processes and IT [30]. In order to gain maximum benefits from technology an organization must be responsive and it should accustomed to changing business challenges requirements and opportunities [14]. Khan [15] presented a coevolutionary framework using K-mediator that aims at reducing gap between business and IT. In the present time the business-IT alignment seems slow rather stationary in view of 
increasing and emerging technologies around the globe. In a recent study an approach has been proposed that helps evaluation of alignment level between business process and supporting software [29].

In this paper co-evolution requirements for a dynamic business have been presented. Also a co-evolution model for business and IT is presented and later the model is validated in a dynamic financial business organization where a change causes a co-evolution. The efficacy of co-evolution requirements is discussed and finally recommendations for effective co-evolution in organizations are presented.

\section{Co-Evolution Model}

Companies are adopting IT function in business processes in order to facilitate customers. Now customers can access a firm's database and give and track their orders online from manufacturing to delivery. Business processes not only aligned with the IT functions but co-evolve as the requirements are changed. Ehlrich et al. [21] introduced the term 'co-evolution' and researchers and practitioners have been using this term in research to explain that evolution of one entity is partially dependant on another entity [22][23][24]. In biology coevolution occurs in an ecosystem in which each living creature has other creatures of the same environment and other creatures are the parts of its environment [24]. In the present study ecosystem comprises of financial institution and related industries that may influence the institution under study. When co-evolution occurs it impacts both individual elements and the environment. Co-evolution concept has been used in variety of areas from biology to commerce and business to technology [8].

In a dynamic business environment business processes keep changing in a fast paced environment and therefore, it is important to know the requirements for a dynamic business environment.In a dynamic business environment new policies, rules, regulations and customer demands change with a passage of time, therefore on one hand new technologies are integrated to support the changes while on the other hand new models are evolved to facilitate in evolution to both the entities. In a dynamic distributed business environment one may expect unusual events and underlying technologies must be able to handle such situations. In dynamic environment business processes should have loose coupling with each other so that propagation of any change is minimum from one process to another [5]. In the event of any partnership the business processes should be changed in order to accommodate new rules, policies that occur due to new collaboration [16].

In view of a dynamic business environment a co-evolution model is presented where business processes (b1, b2, b3) are supported by underlying IT services $(\mathrm{t} 1, \mathrm{t} 2, \mathrm{t} 3)$. Since the business environment is dynamic a change occurs in business processes and a new process b4 is added to the existing processes. In order to meet the evolution requirement in business processes IT services need to be evolved as well and therefore, a new IT services 44 is created. Figure 1 depicts the scenario where different business processes are integrated and process b2 is evolved to b2' and supporting IT service t2 also co-evolved to $\mathrm{t} 2$ '. Also a new business process b4 and its supporting IT service $\mathrm{t} 4$ is added.

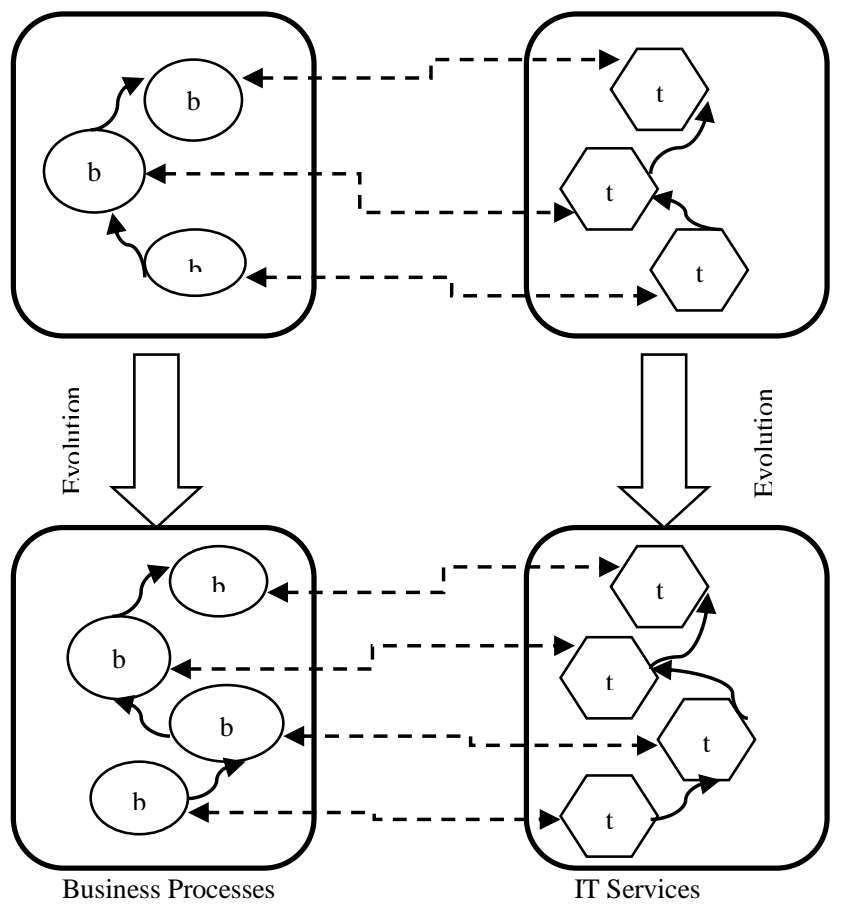

Fig. 1. Business-IT Co-evolution Model

In Figure I it is obvious that adaptability in business or IT function will cause a change in another entity that in turn results a co-evolution. Co-evolution increases efficiency and performance in business and meets customer requirements. It is to be noted that change in a business process or IT can be due to customers' demands or surrounding environment in the marketplace. It is also important for a co-evolution that managers in both business and IT are knowledgeable in each other domains in order to keep co-evolution. When a change occurs in either business requirements or IT function manager of either entity must communicate the supporting function required to co-evolve through the different layers of management and ensure the communication is reached to each level effectively.

\section{A. Efficacy of the Model}

Dynamic business organizations strive to optimize available resources in order to provide efficient services and to meet customers' needs. Since the alignment between business and IT in organizations is persistent and has potential implications researchers give it priority in organizations [17]. Any change in business process or technology may affect the entire business, therefore, it is necessary to consider any change with great care. In a dynamic business environment a co-evolution between business and IT enables organizations to achieve optimization. In order to see the efficacy of the coevolution model a service industry was selected because service requires skilled personnel and an effective and efficient technology for running smooth business [10]. A financial institution (called FI for privacy agreement) was selected due to its dynamic nature of business. Financial institutions are more frequently change requirements and adapt processes and underlying technologies. FI provides effective and efficient services to its customers both online and offline. Recently in board meeting of the institution it was discussed to establish a 
new department that could process customers loan requests in a short period of time. The board decided to approve the establishment of department with required resources. It was noticed the new department required the customers' data on a regular basis so that loan applications could be completed in a minimum time. This process required linkage of other departments with the new department via telecommunication. Customer applications for loan are submitted in a local branch whereas the data is transmitted to other departments immediately so that they could process data and send to the newly established department. In order to handle customers' data in a timely manner different departments also required IT to be updated. Hence the creation of new department caused to update and purchase new telecommunication devices and software. This clearly shows the co-evolution in both business and IT which is in agreement with the co-evolution model. In result of the co-evolution all departments are updated with processes and required technologies. This ensures that the organization is working with the updated information and latest tools available. In the co-evolution model different business processes and technologies are loosely coupled therefore coevolution is easy and the organizations benefit extensively in result of any change in the business.

\section{VALIDATION OF THE MODEL}

In order to validate the model it was decided to collect data by a survey instrument and a case study in a financial institution. A case study approach helps to understand variables in real life situation. A case study provides rich, extensive and complete details [26]. In this study an intrinsic case study is used that helps to understand specific phenomena in an environment. The questions in the survey instrument were divided in three sections. The first part consisted of questions related to measuring performance of the institution; the second part comprised of questions measuring the business and IT strategies and the third part of the questionnaire focused on the organization architecture. All the questions were prepared using on Likert's scale of 1 to 5 where 1 stands for 'Strongly Disagree' (SDA) and 5 stands for 'Strongly Agree' (SA). The remaining values in between are as $2=$ 'Disagree' (DA), 3='Neutral' (NU) and 4='Agree' (AG). The survey instrument was distributed to different employees working in different departments at different levels. Table I shows the parameters used in the questionnaire in order to determine the performance in the organization.

TABLE I. PERFORMANCE PARAMETERS

\begin{tabular}{|l|l|}
\hline Parameter & \multicolumn{1}{|c|}{ Description } \\
\hline QP & Improvement in quality of the product or service \\
\hline CS & Increase in level of customer satisfaction \\
\hline OM & Improvement in organization image \\
\hline RI & Impact in return on investment \\
\hline AG & Increase in annual growth \\
\hline
\end{tabular}

Since a change in requirement has caused creation of a new department in the firm it was necessary to observe the coevolution in other departments so that the co-evolution model could be validated. There were 52 survey instruments distributed among employees at operational and management levels in the firm. Table II and Table III show the expressions used in the questionnaire in order to get data in both business and IT areas.

\section{TABLE II. EXPRESSIONS AND PARAMETERS FOR BUSINESS STRATEGY}

\begin{tabular}{|l|l|}
\hline Parameter & Description \\
\hline IT & Impact of IT in business process \\
\hline PR & Business process reengineering \\
\hline IN & Involvement of IT people in business \\
\hline GR & Growth in business products \\
\hline RK & Willingness to take risks \\
\hline
\end{tabular}

TABLE III. EXPRESSIONS AND PARAMETERS FOR IT STRATEGY

\begin{tabular}{|l|l|}
\hline Parameter & Description \\
\hline TB & Business knowledge in IT plan \\
\hline TA & Acquirement of IT \\
\hline TU & Updating IT for business requirement \\
\hline TC & Cost involve in IT acquisition \\
\hline TE & High level of expertise in IT \\
\hline
\end{tabular}

Out of 52 distributed surveys 36 questionnaires were received from the financial institution (F1). The survey questionnaires were scrutinized and only 29 questionnaires were found complete in all aspects. Cooper \& Schindler [18] stated that a measure is reliable to the degree that it supplies consistent results. Reliability of a questionnaire is important in order to obtain results and hence it was necessary to ensure all items in the questionnaire were reliable. According to [27] an item is called a reliable item when same results are produced by the same items. Internal consistency in reliability is significant which shows consistency in a measuring scale [19]. and to determine internal consistency in a measure reliability of the questions in the survey instrument a reliability test was conducted to determine Cronbach's alpha value [19][20]. After a reliability test it was found 26 questionnaires had Cronbach's alpha value greater than 0.7 that gave confidence to select them for the study. The data collected from the employees were coded into a spreadsheet according to the conventions stated by [28] and assigned numerical values to answers given by respondents in the questionnaires. The values become attributes of the variables. Table IV shows the scores obtained against each parameter used in the questionnaire.

A co-evolution may not take place until all the developing business processes are completely sustained by underpinning evolving technologies. In the financial institution under study it is illustrated from Table IV that absence of latest acquisition of IT (TA) and expertise (TE) may create a gap between evolving business processes and IT as most of the respondents were neutral (value close to 3) for giving answers to such questions. It is obvious from the data that the firm performed well as it received high return on investment (RI) in IT as most of the respondents responded with average value of little higher than 4 (i.e. Agree). This is possible because all the employees of IT department were involved in changing the business requirements as evident from the data parameter IN that has average value higher than 4 . These data were also supported by TB and TU where employees agreed that in planning for IT knowledge of business is essential that helps updating IT for any change in business requirements. 
TABLE IV. AVERAGE SCORES ON LIKERT SCALE

\begin{tabular}{|l|l|c|}
\hline Parameter & Expression & $\begin{array}{l}\text { Average } \\
\text { Score }\end{array}$ \\
\hline QP & Improvement in quality of the product & 3.61 \\
\hline CS & Increase in level of customer satisfaction & 3.52 \\
\hline OM & Improvement in organization image & 3.23 \\
\hline RI & Impact in return on investment & 3.90 \\
\hline AG & Increase in annual growth & 3.71 \\
\hline IT & Impact of IT in business process & 4.23 \\
\hline PR & Business process reengineering & 3.47 \\
\hline IN & Involvement of IT people in business & 4.23 \\
\hline GR & Growth in business products & 3.80 \\
\hline RK & Willingness to take risks & 3.42 \\
\hline TB & Business knowledge in IT plan & 4.09 \\
\hline TA & Acquirement of IT & 3.04 \\
\hline TU & Updating IT for business requirement & 4.14 \\
\hline TC & Cost involve in IT acquisition & 3.33 \\
\hline TE & High level of expertise in IT & 2.95 \\
\hline
\end{tabular}

This clearly shows that when a change was required in the institution knowledgeable people in business from IT were required to update technology in order to support the change. The co-evolution model proves its viability and good results show its feasibility in financial institution.

\section{CONCLUSION}

Co-evolution process is a key of success in a business where both business and IT are evolved to expedite businesses in order to meet requirements. As the Organizations always look for different strategies to optimize their businesses and seldom consider to co-evolve business processes with underlying technologies. In this study it is discussed that the requirements of a dynamic business environment and presented a co-evolution model of business and IT. It is observed in a financial institution that in result of a change in business different business processes and supporting technologies are co-evolved. Co-evolution increases the efficiency and effectiveness of a business that facilitates to meet customer demands.

The model works well when both business and IT coevolve without any delay, however, as organizations tend to change either business process or IT at slow pace the desired results may not be achieved. Therefore, in future, it is anticipated to work on rate of change in business or IT so that organizations could decide to control the speed of co-evolution. The predetermination of co-evolution speed will help organization to manage resources efficiently and effectively and decision makers may find it convenient to manage businesses. In future it is expected to have an evaluation of the co-evolution model in other industries with different methodology.

\section{REFERENCES}

[1] D. Beimborn, J. Franke, H. Wagner, \& T. Weitzel, "The Influence of alignment on the post-implementation success of a core banking information system: an enbedded case study", in Proc $40^{\text {th }}$ Annual
Hawaii International Conference on System Science, Hawaii, USA, 2007.

[2] D. Beimborn, F.Schlosser, \& T. Weitzel, "Proposing a theoretical model for IT governance and IT business alignment", in Proc of the 42nd Hawaii International Conference on System Sciences (HICSS 2009), Hawaii, USA, 2009.

[3] L. Silva, E.Figueroa, \& J. Gonzalez-Reinhart, "Interpreting IS alignment: a multiple case study in professional organizations, information and organization", vol. 17, pp. 232-265, 2007.

[4] T.A. Jenkin, \& E. Chan, "IS project alignment - a process perspective", Journal of Information Technology, vol. 25, pp. 35-55, 2010.

[5] M.A. Khan, \& H. Zedan, "Requirements Analysis for Co-Evolution of Business and Information Technology", Advanced Materials Research, vol. 457-458, pp. 968-973, 2011.

[6] R. Morrison, D. Balasubramaniam, G. Kirby, K. Mickan, B. Wardboys, R. Greenwood, I. Robertson, \& B. Snowdown,B., "A framework for supporting dynamic systems co-evolution”, Autom Softw Eng, vol.14, pp. 261-292, 2007.

[7] D.B. Henderson, \& N. Venkatraman, "Strategic alignment: leveraging information technology for transforming organizations", IBM Systems Journal, vol. 32, pp. 4-16, 1993.

[8] H. Benbya, \& B. McKelvey, "Using coevolutionary and complexity theories to improve IS aligmnment: a multi-level approach", Journal of Information Technology, vol. 21, pp. 284-298, 2006.

[9] S. Chebrolu, "How Does Alignment of Business and IT Strategies Impact Aspects of IT Effectiveness", International Journal of Applied Management and Technology, vol. 12, pp. 1-15, 2013.

[10] C. Suwatana, W. Winai, \& K. Do, "Business-IT Alignment: A Practical Approach", Journal of High Technology Management Research, vol. 25, pp. 132-147, 2014.

[11] L. Richard, \& L. Lucy, "Technology strategy and sustainability of business empirical experiences from Chinese cases", Journal of Technology Management in China, vol. 8, pp. 62-82, 2013.

[12] J. Halamka, "Making smart investments in health information technology: core principles", Health Affairs, vol. 28, pp. 385-389, 2009.

[13] Strnadl., F.,"Aligning business and IT: the process-driven architecture model”, Information Systems Management, vol. 23, pp. 67-77, 2006.

[14] F. A. Cummins, "Building the agile enterprise with SOA, BPM and MBM", Burlington, VT: Morgan Kaufmann,2009.

[15] M.A. Khan, M.A., "An integrated framework to bridging the gap between business and information technology - a co-evolutionary approach", Canadian Journal of Pure and Applied Sciences, vol. 7, pp. 2611-2618, 2013.

[16] J. Meng, S. Sue, H. Lam, \& A. Helal, "Achieving dynamic interorganizational workflow management by integrating business processes, events and rules", in Proc. Hawaii International Conference on System Sciences, 2002, USA.

[17] L. Kappelman, E. McLean, J. Luftman, \& V. Johnson, "Key issues of it organizations and their leadership: the 2013 sim it trends study", MIS Quarterly Executive, vol. 12, pp. 227-240,2013.

[18] C. R. Cooper, and P.S. Schindler, Business research methods, 10th ed., 2008, Boston: McGraw-Hill.

[19] L.J. Cronbach, "Coefficient alpha and the internal structure of tests", Psychometrika, vol. 22, pp. 297-334, 1951.

[20] J. Cortina, "What is coefficient alpha? An examination of theory and methods", Journal of Applied Psychology, vol. 78, pp. 98-104, 1993.

[21] D.R. Ehrlich, \& R.H. Raven, R.H., "Butterflies and plants: a study in co-evolution", Evolution, Vol. 18, pp. 568-608, 1964.

[22] M.P. Koza, \& A. Lewin, A., "The co-evolution of strategic alliances", Organization Science, vol. 9, pp. 255-264, 1998.

[23] B. Mckelvey, "Visioning Leadership vs Distributed Intelligence: Strategy, Microcoevolution, Complexity", in proceedings of EIASM Workshop, 1999. Brussels.

[24] S. Kauffman, The Origins of Order: Self-organization and selection in Evolution, 1993, Oxford University Press. 
[25] J. Martin, W. Jens, W., \& E. Werner, "A model-driven framework for business it alignment", Int. J. Internet and Enterprise Management, vol. 6, pp. $233-247,2010$.

[26] F. Bent, Case Study, In Norman K. Denzin and Yvonna S. Lincoln, eds, The Sage Handbook of Qualitative Research, $4^{\text {th }}$ ed, Chapter 17, pp. 301-316, 2011.

[27] E. Carmines, R. Zeller, R., Reliability and Validity Assessment, 1979., SAGE Publications.
[28] W. Mangione,, Mail Surveys: Improving the Quality, Thousand Oaks, 1995. Sage Publications.

[29] L. Aversano, C. Grasso, and M. Tortorelle, "Managing the alignment between business processes and software systems", Information and Software Technology, vol 72, pp. 171-188, 2016

[30] E. Seman, and J. Salim, "A Model for Business-IT Alignment in Malaysian Public Universities", Procedia Technology, vol. 11, pp. 1135 $-1141,2013$ 